\title{
Modern contraceptive use and factors associated with use among postpartum women in Ethiopia; further analysis of the 2016 Ethiopia demographic and health survey data
}

Gizachew Worku Dagnew ${ }^{1 *} \mathbb{D}$, Melash Belachew Asresie1, Gedefaw Abeje Fekadu and Yared Mulu Gelaw²

\begin{abstract}
Background: The postpartum period is a critical time to improve maternal and child health. It is a time for accessing contraceptives to prevent short inter-pregnancy intervals. More than $95 \%$ of postpartum women do not want to get pregnant within 12 months. However, many women in Ethiopia experience an unintended pregnancy, and there is low information about postpartum contraceptive use among women who have family planning demand. Therefore, this study aimed to estimate the prevalence of postpartum contraceptive use and its predictors among women who give birth 12 months before the survey in Ethiopia.
\end{abstract}

Methods: We used the 2016 Ethiopia demographic health survey data for this analysis. The survey was a communitybased cross-sectional study conducted from January 18 to June 27, 2016. The survey employed a two-stage stratified cluster sampling technique. A total of 2304 postpartum women were included. Bivariate and multivariable logistics regressions were done to identify factors associated with postpartum contraceptive use. A $p$-value $<0.05$ was used to declare statistical significance.

Results: About 23.7\% (23.7, 95\% Cl: 20.7-27.0\%) of postpartum women were using modern contraceptives. Women who were urban residents $(\mathrm{AOR}=2.18 ; 95 \% \mathrm{Cl}: 1.34-3.55)$, those who attended secondary or higher education $(\mathrm{AOR}=$ 1.79; 95\%Cl: 1.04-3.10), women who attended $1-3(\mathrm{AOR}=2.33$; $95 \% \mathrm{Cl}: 1.27-4.25)$ or 4 or more ANC visits (AOR=2.59; $95 \% \mathrm{Cl}: 1.43-4.69)$ and women who delivered at a health facility ( $\mathrm{AOR}=1.86 ; 95 \% \mathrm{Cl}: 1.23-2.81$ ) had higher odds of modern contraceptive use during the postpartum period. Similarly, women who reported the last child was no more wanted (AOR $=1.83 ; 95 \% \mathrm{Cl}: 1.01-3.31$ ), women who decided for contraceptive use (AOR $=2.03 ; 95 \% \mathrm{Cl}: 1.13-3.65)$ and women whose recent child was male ( $\mathrm{AOR}=1.38 ; 95 \% \mathrm{Cl}$ : 1.01-1.88) had higher odds of modern contraceptive use.

Conclusion: Postpartum contraceptive use was low in Ethiopia. Strengthening health facility delivery, promoting girls' education and encouraging women's participation in deciding for contraceptive use would improve the uptake of modern contraceptives use during the postpartum period.

Keywords: Postpartum, Contraceptive, Ethiopia, EDHS

\footnotetext{
*Correspondence: giz.work12@gmail.com

1 Department of Reproductive Health and population studies, School of Public Health, College of Medicine and Health Science, Bahir Dar University, Bahir Dar, Ethiopia

Full list of author information is available at the end of the article
}

(C) The Author(s). 2020 Open Access This article is licensed under a Creative Commons Attribution 4.0 International License, which permits use, sharing, adaptation, distribution and reproduction in any medium or format, as long as you give appropriate credit to the original author(s) and the source, provide a link to the Creative Commons licence, and indicate if changes were made. The images or other third party material in this article are included in the article's Creative Commons licence, unless indicated otherwise in a credit line to the material. If material is not included in the article's Creative Commons licence and your intended use is not permitted by statutory regulation or exceeds the permitted use, you will need to obtain permission directly from the copyright holder. To view a copy of this licence, visit http://creativecommons.org/licenses/by/4.0/ The Creative Commons Public Domain Dedication waiver (http://creativecommons.org/publicdomain/zero/1.0/) applies to the data made available in this article, unless otherwise stated in a credit line to the data. 


\section{Introduction}

Postpartum family planning (PPFP) prevents unintended and closely spaced pregnancies [1]. According to the updated world health organization (WHO) medical eligibility criteria, postpartum and breastfeeding mothers can use progesterone-only pills, implants, the levonorgestrelreleasing IUD, condom/spermicides, male and female sterilization, emergency contraceptive, and diaphragm/ cervical cap. The breastfeeding mothers can also use lactational amenorrhea until 6 months of delivery and combined oral contraceptives after 6 months of delivery [2-4].

Less than $5 \%$ of postpartum women in low-income countries wished to have another pregnancy within 12 months. But a large number of women had a high level of unmet need for contraceptives [5]. Unmet need for family planning (FP) is defined as women who are not pregnant and not postpartum amenorrhoeic and are considered fecund and want to postpone their next birth for two or more years or stop childbearing altogether but are not using a contraceptive method [6].

A survey in 21 low and middle-income countries indicated that $61 \%$ of postpartum women had an unmet need for family planning. The survey added that more $50 \%$ of second births occurred within a short interpregnancy interval [7]. About 20\% of births in SubSaharan Africa occurred with an interval of below 24 months [8].

Short inter-pregnancy interval has a great impact on the child and maternal health. Children born with shortbirth intervals (less than 24 months) are at a higher risk of mortality and undernutrition. Similarly, mothers with short birth intervals are at a higher risk of miscarriage, pre-eclampsia, uterine rupture and other maternal complications [8-13]. The postpartum period is a critical time to address the unmet need for family planning and reduce the risks of closely spaced pregnancies. Spacing pregnancies at least 2 years apart can avert about $10 \%$ of infant deaths and $21 \%$ of child deaths [14].

Although $95 \%$ of women intend to postpone pregnancies for at least 2 years, modern contraceptive use at the postpartum period varies across countries and range from $73.5 \%$ in Zambia to $4 \%$ in Pakistan $[5,15,16]$. Studies in Ethiopia showed that modern contraceptives use in the postpartum period range from $80.2 \%$ in Addis Ababa [17] to $10.2 \%$ in Dabat [18]. Mothers who attended antenatal care (ANC), those who delivered in the health facility, those women with a higher level of education, urban residents, and women with a history of contraceptive use before the index pregnancy were predictors of postpartum contraceptive (PPC) use.

Currently, Ethiopia is implementing different programs to increase postpartum contraceptive use. The national family planning guideline recommends integrating FP counseling during ANC, delivery and post-natal care
(PNC) services [19]. Postpartum women who choose a method during antenatal care or at the time of delivery receive high-quality postpartum family planning services before discharge [20]. Yet, the unmet need for contraceptives is high and many pregnancies have short interpregnancy intervals [7].

Although there is an improvement in modern contraceptives use among married reproductive-age (15-49 years) women, unmet need is still high. Consequently, there are high numbers of undesired births, short interpregnancy interval and neonatal mortality [6]. Furthermore, there is little information about PPC use, especially among women who have a demand for family planning. Also, most published research works did not include potential predictor variables like knowledge on ovulation, women participation for decision making, birth interval and wantedness of the last-child.

Therefore, this analysis was done to assess the prevalence of postpartum contraceptive use and its predictors among women who have a demand for family planning in Ethiopia. The findings of this study can help to design an effective strategy to prevent unintended pregnancy and short inter-pregnancy interval.

\section{Methods}

Data

We used the 2016 EDHS data, collected from January 18 to July 27,2016 , from all administrative regions. It was a community-based cross-sectional survey. A total of 15,683 reproductive age (15-49 years) women were included in the survey. The 2016 EDHS used a two-stage stratified cluster random sampling technique to ensure the representativeness of the sample by regions and residence. The survey covered all administrative regions. Initially, each region was stratified into urban and rural areas yielding 21 sampling strata. After stratification, a total of 645 enumeration areas (202 in urban areas and 443 in rural areas) were selected with probability proportional to enumeration are size based on the 2007 Ethiopia population and housing census. A household listing operation was done from September to December 2015. Then, 28 households from each cluster were selected using a systematic random sampling technique [6].

This analysis included all women who were married/in sexual union, non-pregnant, and gave birth within 12 months of the survey. Women who have a desire for childbirth within 2 years were excluded from the analysis. Based on these criteria, a total of 2304 women were included in the final model (Fig. 1).

\section{Measurements}

Outcome variable

The outcome of this analysis was postpartum contraceptive use; a variable with two outcomes (yes/no). It was 


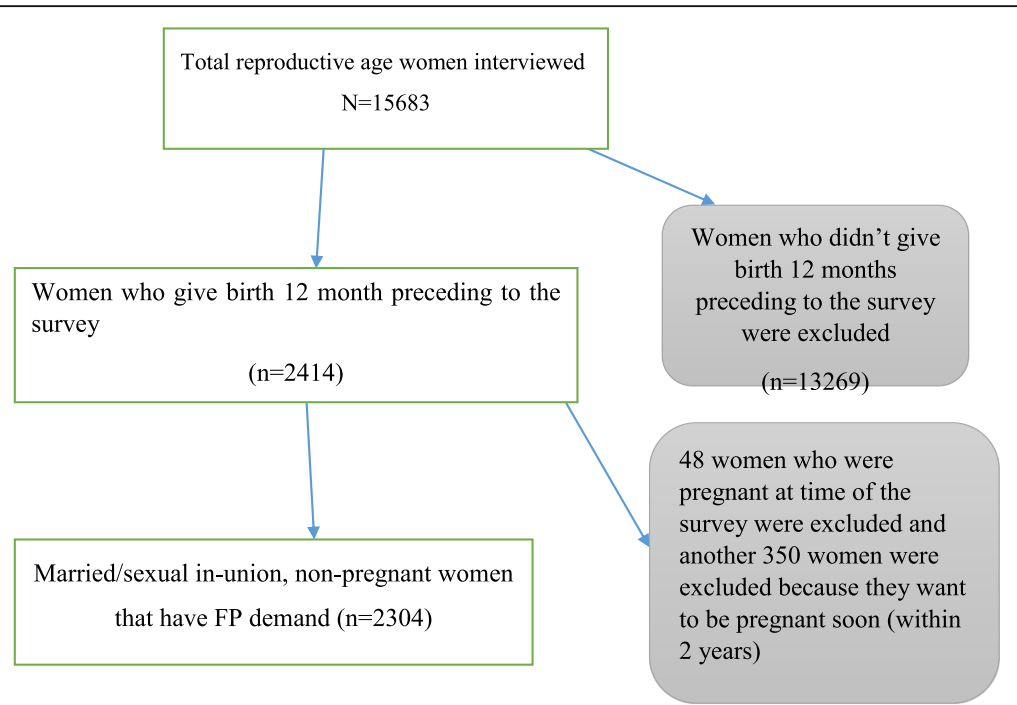

Fig. 1 Schematic presentation to select women included to study postpartum family planning use and factors associated with use from the 2016 Ethiopia Demographic and Health Surveys

measured based on the woman's self-report of modern contraceptive use at the time of the survey (current use). Modern contraceptive methods reported in this study include; female sterilization, implant, intrauterine device (IUD), injectable, oral contraceptive, emergency contraceptive, condom, lactational amenorrhea and periodic abstinence [6].

\section{Independent variables}

\section{The socio-demographic variables}

nclude women age (15-24, 25-34 and $\geq 35$ years), residence(urban and rural), religion (Christian, Muslim and others), women's education status (no formal education, primary, and secondary or above), employment status (working and not working), region (Tigray, Afar, Amhara, Oromia, Somali, Benshaguel, South Nation Nationality People republic (SNNPR), Gambella, Harari, Addis Ababa, and Dire Dawa) and wealth index (poor, middle and rich).

\section{Reproductive health and related variables}

Include; the number of under-five children in the households (one and more than one), number of living children (one, 2-4 and $\geq 5$ ), birth order (first, $2-4$, and $\geq 5$ ), preceding birth interval ( $\leq 24$ months, $\geq 25$ months and no previous birth), wantedness of the last child (wanted, wanted later, and wanted no more), sex of index child (male and female), duration after childbirth (1-2 months, 3-6 months, and 7-12 months), participation on contraceptive use decision (yes/no), visited by a health worker (yes/no), and exposure to family planning messages on mass media (newspaper, radio, television, or mobile SMS text) (yes/no).
The maternal health service use related variables include ANC attendance (no ANC, 1-3 ANC and $\geq 4$ ANC), place of delivery (health facility and home) and PNC attendance (yes/no).

\section{PNC attendance}

Postnatal check includes women who received at least one PNC check from a doctor, midwife, nurse, or health extension worker after delivery or after discharge/delivery at home before 42 days of delivery [6]. This was measured based on the woman's response to a question of whether she had this visit or not.

\section{Women participation in decision making for contraceptive use} women were considered as participated when the women reported that she decided contraceptive use by herself or jointly with her husband [6].

\section{Statistical analysis}

We used STATA 14.0 for this analysis. Descriptive statistics were calculated for all variables. Data were weighted to ensure the representativeness of the survey results at the regional level and by residence, and to account for non-response. Furthermore, the analysis was adjusted to account for the complex survey design and robust standard errors (stratification and clustering) using the 'svy' command in Stata.

Bivariate logistics regression analysis was conducted to select the candidate variable for multivariable logistics regression. Variables with a $p$-value $\leq 0.2$ in the binary logistic regression analysis were included in the multivariable logistic regression model. Multicollinearity 
between each explanatory variable was checked by using the 'pwcorr' command in Stata. Model fitness was checked by using the Hosmer Lemeshow's model good fit $(p>0.05)$ [21].

The multivariable analysis was done to identify factors associated with postpartum contraceptive use. Only variables with a $p$-value of less than 0.05 in the multivariable analysis were considered statistically significant. The adjusted odds ratios (AOR) with its corresponding 95\% confidence interval were presented in the results section.

\section{Results}

\section{Socio-demographic characteristics of women}

A total of 2304 reproductive-age (15-49 years) women who gave birth within 12 months of the survey were included in the analysis. The mean age ( $\pm \mathrm{sd})$ of the study participants was $28.0( \pm 6.6)$ years. Almost half $(49.0 \%)$ of them were aged $25-34$ years. About $88 \%$ of women were rural residents. Nearly $60 \%$ of participants did not attend formal education. More than $90 \%$ of participants were from major regions (Oromia 44.7\%, Amhara 19.7\%, SNNPR 20.5\% and Tigray accounts $7.4 \%$ ), $4.6 \%$ of participants were from developing regions (2.4\% Somali, $1.1 \%$ Benshangul, 0.7 Afar, Harari ad Gambela accounts each $0.2 \%$ ), and the remaining $3 \%$ comes from two city administration (2.6\% Addis Ababa, 0.4\% Diredawa) (Table 1).

\section{Reproductive health characteristics and maternal health service use}

Seven-hundred thirty-seven (32.0\%) study participants had five or more living children. One-hundred eighty-eight (40.6\%) participants want no more children in the future. Two-hundred eighty-six (12.4\%) births had a short interpregnancy interval ( $\leq 24$ months). Eight-hundred thirtyfour $(36.2 \%)$ of the index child was fourth or more in terms of birth order. About 1138 (49.4\%) of the index child was male sex. Sixty-nine percent of women reported that they attended at least one ANC visits and $40.7 \%$ of women reported that they delivered at health facilities. One-third (34\%) of the study participants were visited by field workers in the last 12 months, ad $66.8 \%$ of women report that they visited the health facility in the same period (Table 1).

\section{Postpartum contraceptive use}

The analysis identified that $23.7 \%$ (95\%CI: 20.7-27.0\%) postpartum women were using modern contraceptive methods at the time of the survey. The most common contraceptive used were injectable (69.8\%), followed by implants $(17.2 \%)$, and the least frequent contraceptive method used was male condom (0.2) (Fig. 2).

\section{Postpartum contraceptive use by background characteristics}

Postpartum contraceptive use varied by region. The level of use was lowest in Somali (2\%) and Afar (13.6\%) regions. The highest level of use was in Addis Ababa (64.6\%) and SNNPR (37.1\% (Fig. 3).

The level of postpartum contraceptive use was relatively lower among women aged more than 35 years compared to those aged 15-24 years. Similarly, postpartum contraceptive use was higher among women with few numbers of children compared to those with a high number of children. For example, postpartum contraceptive use among women with only one living child was $32.2 \%$ compared to $13.7 \%$ among women who had more than five children. On the other hand, postpartum contraceptive use was relatively higher among rich women compared to the poor (Table 2).

Postpartum contraceptive use was also higher among women who delivered at health facilities (37.3\%) compared to women who delivered at home (14.4\%). Similarly, PPC use was relatively high among women who attended ANC (34.3\%) compared to those who did not attend ANC (8.9\%).

\section{Factors associated with postpartum contraceptive use}

On multivariable logistics regression, residence, educational status, place of delivery, ANC attendance, participation on FP use, wantedness and sex of the last child were statistically significant at $p$-value $<0.05$. Women who attended secondary or higher education had higher odds $(\mathrm{AOR}=1.81 ; 95 \% \mathrm{CI}: 1.04-3.12)$ of postpartum contraceptive use compared to women who did not attend formal education. Urban women had higher odds $(\mathrm{AOR}=2.20$; 95\%CI: 1.35-3.60) of PPC use compared to rural women. Women who delivered at health facility had higher odd $(\mathrm{AOR}=1.85$; 95\%CI: $1.22-2.81)$ of PPC use compared to those who delivered at home. Similarly, women who attend $1-3$ ANC visits (AOR $=2.33$; 95\%CI: $1.28-4.24$ ) or 4 or more $\mathrm{ANC}$ ( $\mathrm{AOR}=2.59$; 95\% CI: 1.44-4.72) visits had high odds of PPC use compared to those who didn't have ANC visit. Similarly, the odd of postpartum contraceptive use were higher among women whose recent birth was wanted later ( $\mathrm{AOR}=1.81 ; 95 \% \mathrm{CI}: 1.19-2.77)$ and no more wanted $(\mathrm{AOR}=1.83 ; 95 \% \mathrm{CI}: 1.01-3.31)$ compared to women whose recent birth was wanted soon (Table 2).

\section{Discussion}

The analysis included women who did not intend to have children soon. That means, only women who had a demand for modern contraceptives were included in this analysis. But only $23.7 \%$ of Ethiopian women were using modern contraceptives during the postpartum time. The implication is that most Ethiopian women were exposed to unintended pregnancy during the postpartum period. 
Table 1 Sociodemographic, Reproductive health and maternal health service use characteristics of married/ in union postpartum women in Ethiopia, 2016 EDHS

\begin{tabular}{|c|c|c|}
\hline Variables $(n=2304)$ & Categories & $\begin{array}{l}\text { Number } \\
(\%)\end{array}$ \\
\hline \multirow[t]{3}{*}{ Age in years } & $15-24$ & 735 (31.9) \\
\hline & $25-34$ & $\begin{array}{l}1129 \\
(49.0)\end{array}$ \\
\hline & $\geq 35$ & $440(19.1)$ \\
\hline \multirow[t]{2}{*}{ Residence } & Urban & $286(12.4)$ \\
\hline & Rural & $\begin{array}{l}2018 \\
(87.6)\end{array}$ \\
\hline \multirow[t]{3}{*}{ Wealth index } & Poor & $\begin{array}{l}1010 \\
(43.9)\end{array}$ \\
\hline & Middle & $482(20.9)$ \\
\hline & Rich & $811(35.2)$ \\
\hline \multirow[t]{3}{*}{ Educational status } & $\begin{array}{l}\text { No formal } \\
\text { education }\end{array}$ & $\begin{array}{l}1330 \\
(57.7)\end{array}$ \\
\hline & Primary & 769 (33.4) \\
\hline & $\begin{array}{l}\text { Secondary or } \\
\text { above }\end{array}$ & $205(8.9)$ \\
\hline \multirow[t]{3}{*}{ Religion } & Christian & $\begin{array}{l}1287 \\
(55.8)\end{array}$ \\
\hline & Muslim & $960(41.6)$ \\
\hline & Others & $58(2.5)$ \\
\hline \multirow[t]{2}{*}{ Working status } & Not working & $\begin{array}{l}1410 \\
(61.2)\end{array}$ \\
\hline & Working & $894(38.8)$ \\
\hline \multirow[t]{3}{*}{ Number of living children } & One & $523(22.7)$ \\
\hline & $2-4$ & $\begin{array}{l}1044 \\
(45.3)\end{array}$ \\
\hline & $5+$ & $737(32.0)$ \\
\hline \multirow[t]{3}{*}{ Preceding birth interval } & $\leq 24$ months & $286(12.4)$ \\
\hline & $\geq 25$ months & $\begin{array}{l}1519 \\
(65.9)\end{array}$ \\
\hline & $\begin{array}{l}\text { No preceding } \\
\text { birth }\end{array}$ & $498(21.6)$ \\
\hline \multirow[t]{3}{*}{ Birth order of current child } & First & $495(21.5)$ \\
\hline & $2-4$ & $976(42.3)$ \\
\hline & $5+$ & $834(36.2)$ \\
\hline \multirow{2}{*}{$\begin{array}{l}\text { Women had participated in deciding for } \\
\text { FP use }\end{array}$} & No & $356(15.5)$ \\
\hline & Yes & $\begin{array}{l}1948 \\
(84.5)\end{array}$ \\
\hline \multirow[t]{3}{*}{ ANC attendant } & No ANC & $710(30.8)$ \\
\hline & 1-3 ANC & 775 (33.6) \\
\hline & $4+$ ANC & $820(35.6)$ \\
\hline \multirow[t]{2}{*}{ Place of delivery } & Home & $\begin{array}{l}1366 \\
(59.3)\end{array}$ \\
\hline & Health facility & $938(40.7)$ \\
\hline Attending at least one Postnatal visit & No & $\begin{array}{l}1826 \\
(79.2)\end{array}$ \\
\hline
\end{tabular}

Table 1 Sociodemographic, Reproductive health and maternal health service use characteristics of married/ in union postpartum women in Ethiopia, 2016 EDHS (Continued)

\begin{tabular}{lll}
\hline Variables $(n=2304)$ & Categories & $\begin{array}{l}\text { Number } \\
(\%)\end{array}$ \\
\hline \multirow{3}{*}{ Duration of postpartum } & Yes & $479(20.8)$ \\
& $1-2$ months & $593(25.7)$ \\
& $3-6$ months & 1033 \\
& & $(44.8)$ \\
Media Exposure for FP messages & $7-12$ months & $678(29.4)$ \\
& No & 1714 \\
& & $(74.4)$ \\
& Yes & $590(25.6)$ \\
\hline
\end{tabular}

The level of use was lower than the study in Kenya (86.3\%) [22] and other small scale studies in Ethiopia; Hossana (72.9\%), Dessie (54.7\%) and Addis Ababa [17, 23, 24]. The reason for the low level of postpartum contraceptive use in this study compared to other studies might be the difference in the educational status of the study participants. Almost all women in the Kenyan study attended formal education [22]. In the Hossana, Dessie and Addis Ababa studies, $68-89 \%$ of the participants attended formal education [17, 23, 24] compared to only $42.3 \%$ in this study. Education can increase women's awareness and level of understanding about the risk of being pregnant in the postpartum period. The other reason for the lower use in this study might be the difference in health facility delivery. In the current study, only $40.7 \%$ of women delivered at a health facility, but more than $80 \%$ of women who participated in the above studies delivered in health facilities [17, 23, 24]. Women who delivered at the health facilities are more likely to be counseled about postpartum family planning and initiated to use a contraceptive.

More than three-fourths of women reported using short-acting contraceptive methods $(69.8 \%$ injectable, and $6.8 \%$ pills were the predominant methods). This may be related to women's preference for short-acting methods, provider bias or limited access to long-acting methods [25]. These dominant types of contraceptive use were observed in different studies, especially in low and middle-income countries [26-29].

The current study revealed that education is positively associated with postpartum contraceptive use. The odds of contraceptive use was higher among women who attended secondary or higher education compared to those who did not attend. This finding was in line with studies done in Uganda and other studies in Ethiopia [5, $16,23,24]$. The reason for this might be that educated women can understand the risk of a short interpregnancy interval and the benefits of contraceptive use during the postpartum period. 


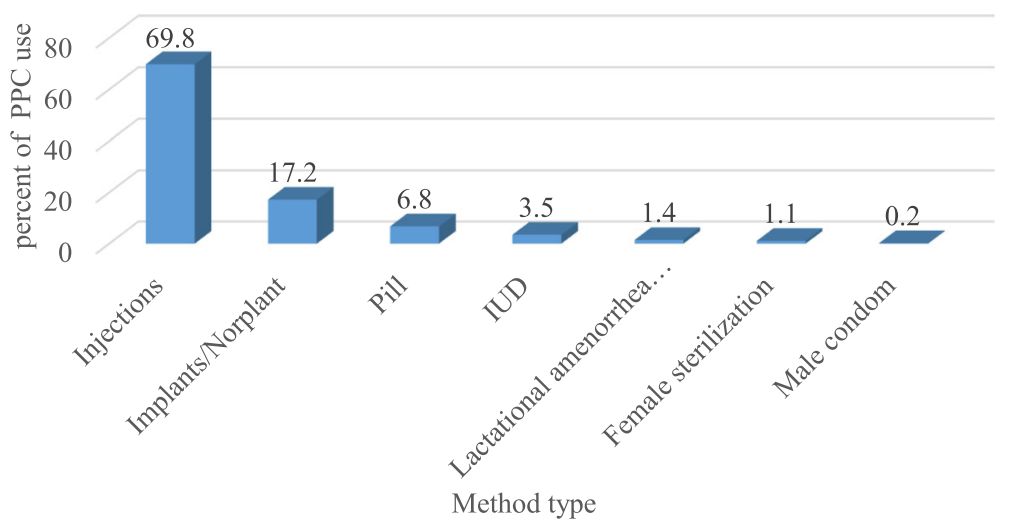

Fig. 2 Contraceptive method mix among postpartum women in Ethiopia; EDHS 2016

The study showed that urban women had higher odds of modern contraceptive use in the postpartum period compared to their rural counterparts. The reason for this might be that urban women have better access for maternal health services including contraceptives compared to rural women. This finding was in line with a study in Northwest Ethiopia [18].

This analysis showed that ANC attendance was positively associated with postpartum contraceptive use. The possible explanation for this is that women who attend ANC were more likely to be counseled about postpartum contraceptive use. Such counseling and information may have increased women's knowledge for family planning and subsequent uptake of contraception during the postpartum period [30]. This finding was in line with studies from Mexico, Nigeria, Ghana and Gondar [29, 31-33]. Similarly, women who delivered at a health facility had higher odds of postpartum contraceptive use compared to women who delivered at home. The possible explanation for this finding might contraceptive information and initiation for women who delivered at a health facility. FP services are integrated with the delivery service in Ethiopia. This is indicated in the Ethiopian family planning guideline [19]. This information provision and counseling before discharge may increase the subsequent uptake of contraceptives [34]. This finding is consistent with the studies done in different countries including Ethiopia [5, 16, 18, 35, 36].

Wantedness of the recent child was another factor associated with postpartum contraceptive use. Mothers who reported their recent birth was wanted later and not wanted at all had high odds of postpartum contraceptive use compared to women who reported their recent child was wanted at the time of the survey. The implication is that women who achieved or surpassed the desired number of children were more likely to use contraceptives during the postpartum period. This implies that women who experienced unwanted birth are more likely to use contraceptives during the postpartum period to prevent additional unwanted children [22].

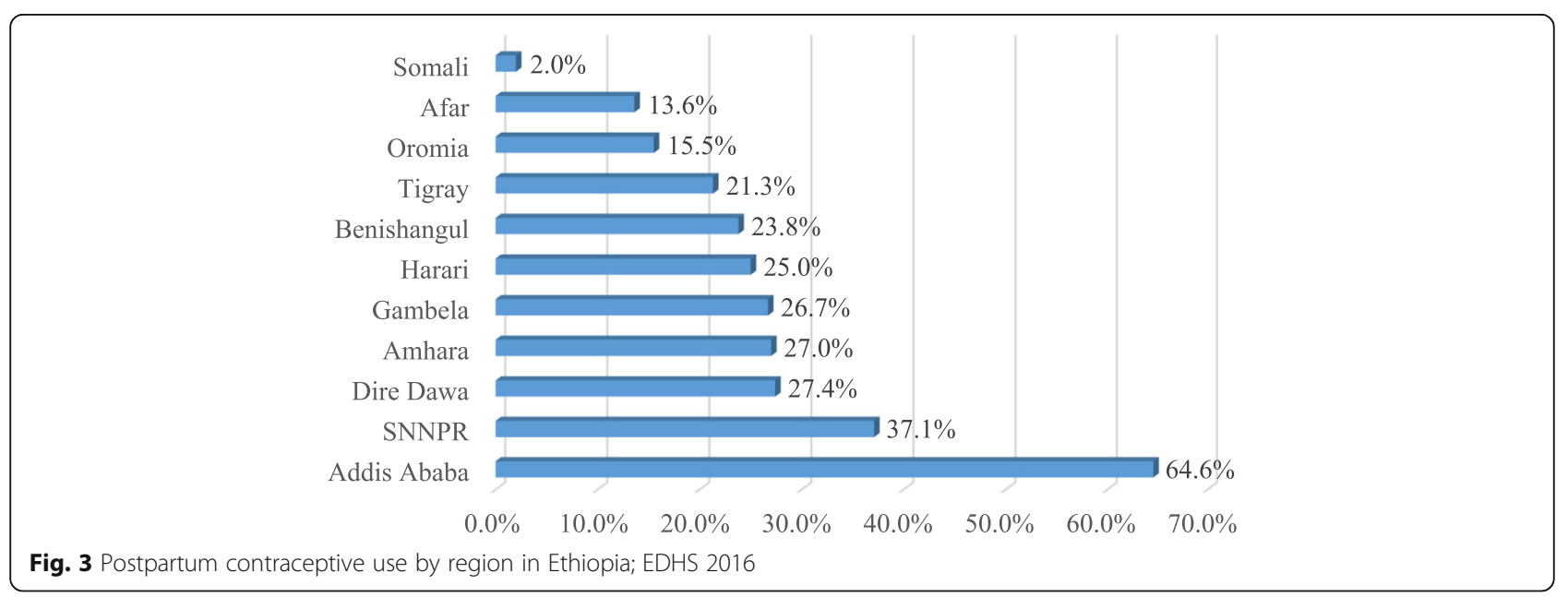


Table 2 Factors associated with PPC use among married/in-union women in Ethiopia; EDHS 2016

\begin{tabular}{|c|c|c|c|c|c|c|}
\hline \multirow[t]{2}{*}{ Variables $(n=2304)$} & \multicolumn{2}{|c|}{ Current FP use } & \multirow[t]{2}{*}{ COR } & \multirow[t]{2}{*}{$95 \% \mathrm{Cl}$} & \multirow[t]{2}{*}{ AOR } & \multirow[t]{2}{*}{$95 \% \mathrm{Cl}$} \\
\hline & Yes (\%) & $\mathrm{No}(\%)$ & & & & \\
\hline \multicolumn{7}{|l|}{ Age } \\
\hline $15-24$ & 28.2 & 71.8 & $1.90^{*}$ & $1.17-3.08$ & 1.41 & $0.80-2.49$ \\
\hline $25-34$ & 23.4 & 76.6 & 1.48 & $0.91-2.40$ & 1.11 & $0.65-1.87$ \\
\hline $35+$ & 17.1 & 82.9 & 1 & & 1 & \\
\hline \multicolumn{7}{|l|}{ Place of residence } \\
\hline Rural & 19.7 & 80.3 & 1 & & 1 & \\
\hline Urban & 52.1 & 47.9 & $4.43^{* * *}$ & $3.03-6.49$ & $2.20^{* *}$ & $1.35-3.60$ \\
\hline \multicolumn{7}{|l|}{ Educational status } \\
\hline No formal education & 16.2 & 83.8 & 1 & & 1 & \\
\hline Primary & 30 & 70 & $2.21 * * *$ & $1.58-3.11$ & 1.41 & $0.96-2.05$ \\
\hline Secondary ad above & 49.3 & 50.7 & $5.03^{* * *}$ & $3.20-7.93$ & $1.81^{*}$ & $1.04-3.12$ \\
\hline \multicolumn{7}{|l|}{ Wealth index } \\
\hline Poor & 15.1 & 84.9 & 1 & & 1 & \\
\hline Middle & 22.4 & 77.6 & $1.63^{*}$ & $1.06-2.49$ & 1.38 & $0.87-2.19$ \\
\hline Reach & 35.3 & 64.7 & $3.07^{* * *}$ & $2.11-4.47$ & 1.46 & $0.94-2.27$ \\
\hline \multicolumn{7}{|l|}{ No. of ANC visit } \\
\hline No ANC visit & 8.9 & 91.1 & 1 & & 1 & 1 \\
\hline 1-3 ANC & 26.1 & 73.9 & $3.60^{* * *}$ & $2.10-6.18$ & $2.33^{* *}$ & $1.28-4.24$ \\
\hline $4+$ ANC & 34.3 & 65.7 & $5.32^{* * *}$ & $3.13-9.03$ & $2.61^{* *}$ & $1.44-4.72$ \\
\hline \multicolumn{7}{|l|}{ Place of delivery } \\
\hline Health facility & 37.3 & 62.7 & $3.54^{* * *}$ & $2.57-4.86$ & $1.85^{* *}$ & $1.22-2.81$ \\
\hline Home & 14.4 & 85.6 & 1 & & 1 & \\
\hline \multicolumn{7}{|l|}{ Received PNC services } \\
\hline No & 20.4 & 79.6 & 1 & & 1 & \\
\hline Yes & 36.2 & 63.8 & $2.21^{* * *}$ & $1.61-3.03$ & 0.87 & $0.58-1.31$ \\
\hline \multicolumn{7}{|l|}{ Sex of the last child } \\
\hline Male & 26.4 & 73.6 & $1.34^{*}$ & $1.01-1.77$ & $1.38^{*}$ & $1.01-1.88$ \\
\hline Female & 21.1 & 78.9 & 1 & & 1 & \\
\hline \multicolumn{7}{|c|}{ Wanted status of last-child } \\
\hline Wanted soon & 22.2 & 77.8 & 1 & & 1 & \\
\hline Wanted later & 29.6 & 70.4 & 1.48 & $0.99-2.20$ & $1.81^{* *}$ & $1.19-2.77$ \\
\hline Wanted no more & 23.4 & 76.6 & 1.07 & $0.63-1.82$ & $1.83^{*}$ & $1.01-3.31$ \\
\hline \multicolumn{7}{|l|}{ Duration of postpartum } \\
\hline $1-2$ months & 23.3 & 76.7 & 1 & & 1 & \\
\hline $3-6$ months & 22.2 & 77.8 & 1 & & 1.09 & $0.72-1.64$ \\
\hline 7-12 months & 26.3 & 73.7 & 1.23 & $0.90-1.67$ & 1.10 & $0.71-1.71$ \\
\hline \multicolumn{7}{|c|}{ Media exposure for FP messages } \\
\hline No & 20.8 & 79.2 & 1 & & 1 & \\
\hline Yes & 32.3 & 67.7 & $1.82^{* *}$ & $1.30-2.55$ & 0.88 & $0.60-1.30$ \\
\hline \multicolumn{7}{|l|}{ Participation in FP use } \\
\hline No & 14.2 & 85.8 & 1 & & 1 & \\
\hline Yes & 25.4 & 74.6 & $2.06^{* *}$ & $1.22-3.48$ & $2.01^{*}$ & $1.14-3.55$ \\
\hline
\end{tabular}


Table 2 Factors associated with PPC use among married/in-union women in Ethiopia; EDHS 2016 (Continued)

\begin{tabular}{|c|c|c|c|c|c|c|}
\hline \multirow[t]{2}{*}{ Variables $(n=2304)$} & \multicolumn{2}{|c|}{ Current FP use } & \multirow[t]{2}{*}{ COR } & \multirow[t]{2}{*}{$95 \% \mathrm{Cl}$} & \multirow[t]{2}{*}{$\mathrm{AOR}$} & \multirow[t]{2}{*}{$95 \% \mathrm{Cl}$} \\
\hline & Yes (\%) & $\mathrm{No}(\%)$ & & & & \\
\hline \multicolumn{7}{|c|}{ Visited by fieldworker in the last 12 months } \\
\hline No & 20.6 & 79.4 & 1 & & 1 & \\
\hline Yes & 30 & 70 & $1.66^{* *}$ & $1.19-2.31$ & 1.39 & $0.98-1.97$ \\
\hline
\end{tabular}

${ }^{* * *} p<0.001,{ }^{* *} p<0.01, * p<0.05$, COR Crude Odd Ratio, Cl Confidence Interval, AOR Adjusted Odd Ratio

This finding was consistent with the study done in Nepal [37].

Women who decided contraceptive use by themselves or jointly with their partner were more likely to use contraceptives during the postpartum period. This is related to women's autonomy. This finding was supported by findings from other studies [38-40].

This study showed that the sex of the recent child was significantly associated with postpartum contraceptive use. Women whose recent child was male had higher odds of postpartum contraceptive use. This might be due to sex preference [41, 42]. This is supported by studies done in China, Nepal, India, and other global context studies [43-46].

\section{Conclusions}

Postpartum contraceptive use was low in Ethiopia. More than three-fourths of women have had a risk of facing mistimed or unwanted pregnancy. Urban women, women who attended secondary or higher levels of education, women who attended ANC or delivered at health facilities and women with unintended birth had higher odds of postpartum contraceptive use. Similarly, women who participated in a decision regarding contraceptive use and women whose recent child was male had higher odds of postpartum contraceptive use. Strengthening skilled maternal health services use is recommended to increase postpartum contraceptive uptake. Additionally, promoting girls' education, and empowering women to participate in deciding for contraceptive use are recommended to increase postpartum contraceptive use.

\section{Abbreviations}

ANC: Antenatal Care; AOR: Adjusted Odds Ratio; Cl: Confidence Interval; EDHS: Ethiopian Demographic and Health Survey; FP: Family Planning; IUD: Intrauterine Device; PPC: Postpartum Contraceptive

\section{Acknowledgments}

We would like to thank the DHS Program for allowing us to use the 2016 EDHS data for this analysis.

\section{Authors' contributions}

GWD conceived and designed the study. GWD, MBA, GAF, and YMG equally involved in the analysis, interpretation, and writing of the results. All authors read and approved the final manuscript.

\section{Funding}

No funding was obtained for this analysis.
Availability of data and materials

The datasets used for this study are available from the DHS program website [http://dhsprogram.com/data/] upon permission.

\section{Ethics approval}

The 2016 EDHS protocol was reviewed and approved by the National Ethics Review Committee of the Federal Democratic Republic of Ethiopia, Ministry of Science and Technology and the Institutional Review Board of ICF International. The STATA format data was downloaded from the DHS program with permission.

Consent for publication

Not applicable.

Competing interests

All authors declare that they do not have competing interests.

\section{Author details}

${ }^{1}$ Department of Reproductive Health and population studies, School of Public Health, College of Medicine and Health Science, Bahir Dar University, Bahir Dar, Ethiopia. ${ }^{2}$ Department of Health Service Management, School of Public Health, College of Medicine and Health Sciences, Bahir Dar University, Bahir Dar, Ethiopia.

Received: 31 March 2020 Accepted: 29 April 2020

Published online: 12 May 2020

\section{References}

1. Bakamjian L. Programming strategies for postpartum family planning; 2013.

2. Altshuler AL, Gaffield ME, Kiarie JN. The WHO's medical eligibility criteria for contraceptive use: 20 years of global guidance. Curr Opin Obstet Gynecol. 2015;27(6):451-9.

3. World Health Organization, Department of Reproductive Health and Research (WHO/RHR) and Johns Hopkins Bloomberg School of Public Health. Center for Communications Programs (CCP), Knowledge for Health Project. Family Planning: A global handbook for providers (2018 update). CCP and WHO/RHR. http://info.k4health.org/globalhandbook: Baltimore and Geneva; 2018

4. Berens P, Labbok M, A.o.B. Medicine. ABM clinical protocol\# 13: contraception during breastfeeding, revised 2015. Breastfeed Med. 2015; 10(1):3-12.

5. Pasha $\mathrm{O}$, et al. Postpartum contraceptive use and unmet need for family planning in five low-income countries. Reprod Health. 2015;12(2):S11.

6. Central Statistical Agency (CSA) [Ethiopia] and ICF. Ethiopia Demographic and Health Survey 2016. Addis Ababa and Rockville: CSA and ICF; 2016.

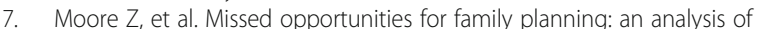
pregnancy risk and contraceptive method use among postpartum women in 21 low-and middle-income countries. Contraception. 2015;92(1):31-9.

8. Rutstein SO. Trends in birth spacing. In: DHS Comparative Reports No. 28. Calverton: ICF Macro; 2011.

9. Klerman LV, Cliver SP, Goldenberg RL. The impact of short interpregnancy intervals on pregnancy outcomes in a low-income population. Am J Public Health. 1998:88(8):1182-5.

10. Fotso JC, et al. Birth spacing and child mortality: an analysis of prospective data from the Nairobi urban health and demographic surveillance system. J Biosoc Sci. 2013;45(6):779-98.

11. Kinney MV, et al. Sub-Saharan Africa's mothers, newborns, and children: where and why do they die? PLoS Med. 2010;7(6):e1000294. 
12. Hogue CJ, et al. Racial disparities in preterm birth rates and short interpregnancy interval: an overview. Acta Obstet Gynecol Scand. 2011;90(12): $1317-24$.

13. Kozuki N, Walker N. Exploring the association between short/long preceding birth intervals and child mortality: using reference birth interval children of the same mother as a comparison. BMC Public Health. 2013;13(Suppl 3):S6.

14. Gaffield ME, Egan S, Temmerman M. It's about time: WHO and partners release programming strategies for postpartum family planning. Glob Health Sci Pract. 2014;2(1):4-9.

15. Borda M, Winfrey W. Postpartum fertility and contraception: an analysis of findings from 17 countries. Baltimore: Jhpiego; 2010.

16. Rutaremwa $\mathrm{G}$, et al. Predictors of modern contraceptive use during the postpartum period among women in Uganda: a population-based crosssectional study. BMC Public Health. 2015;15(1):262.

17. Gebremedhin AY, et al. Family planning use and its associated factors among women in the extended postpartum period in Addis Ababa, Ethiopia. Contracept Reprod Med. 2018;3(1):1-8.

18. Mengesha ZB, Worku AG, Feleke SA. Contraceptive adoption in the extended postpartum period is low in Northwest Ethiopia. BMC Pregnancy Childbirth. 2015;15(1):160

19. Kesetebirhan A. National Guideline for family planning Services in Ethiopia: The Federal Democratic Republic of Ethiopia, Ministry of Health; 2011. http://phe-ethiopia.org/resadmin/uploads/attachment.

20. World Health Organization. Programming strategies for postpartum family planning. 2013.

21. Hosmer S Jr, Lemeshow DW, Sturdivant RX. Applied logistic regression, vol. 398. Wiley; 2013

22. Rose Jalang'o FT, Barasa SO, Njoroge P. Determinants of contraceptive use among postpartum women in a county hospital in rural KENYA. BMC Public Health. 2017;17:604

23. Gejo NG, Anshebo AA, Dinsa LH. Postpartum modern contraceptive use and associated factors in Hossana town. PLoS One. 2019;14(5):e0217167.

24. Tegegn M, Arefaynie M, Tiruye TY. Unmet need for modern contraceptives and associated factors among women in the extended postpartum period in Dessie town, Ethiopia. Contracept Reprod Med. 2017;2(1):21.

25. World Health Organization. Medical eligibility criteria for contraceptive use. Fourth Ed. Geneva: Department of Reproductive Health and Research, World Health Organization; 2010. ISBN: 9241563885, 9789241563888.

26. Eliason $\mathrm{S}$, et al. Factors influencing the intention of women in rural Ghana to adopt postpartum family planning. Reprod Health. 2013;10(1):34.

27. Mumah JN, et al. Contraceptive adoption, discontinuation, and switching among postpartum women in Nairobi's urban slums. Stud Fam Plan. 2015; 46(4):369-86.

28. Ross J, Keesbury J, Hardee K. Trends in the contraceptive method mix in low-and middle-income countries: an analysis using a new "average deviation" measure. Glob Health Sci Pract. 2015:3(1):34-55.

29. Abera Y, Mengesha ZB, Tessema GA. Postpartum contraceptive use in Gondar town, Northwest Ethiopia: a community-based cross-sectional study. BMC Womens Health. 2015;15(1):19.

30. Vernon R. Meeting the family planning needs of postpartum women. Stud Fam Plan. 2009;40(3):235-45.

31. Barber SL. Family planning advice and postpartum contraceptive use among low-income women in Mexico. Int Fam Plan Perspect. 2007;33:6-12.

32. Adanikin Al, Onwudiegwu U, Loto OM. Influence of multiple antenatal counseling sessions on modern contraceptive uptake in Nigeria. Eur J Contracept Reprod Health Care. 2013;18(5):381-7.

33. Coomson Jl, Manu A. Determinants of modern contraceptive use among postpartum women in two health facilities in urban Ghana: a cross-sectional study. Contracept Reprod Med. 2019:4(1):17.

34. Cleland J, Shah $\mathrm{H}$, Daniele M. Interventions to improve postpartum family planning in low-and middle-income countries: program implications and research priorities. Stud Fam Plan. 2015;46(4):423-41.

35. Tessema GA, et al. Association between skilled maternal healthcare and postpartum contraceptive use in Ethiopia. BMC Pregnancy Childbirth. 2018; 18(1):172

36. Tappis $\mathrm{H}$, et al. The role of quality health services and discussion about birth spacing in postpartum contraceptive use in Sindh, Pakistan: a multilevel analysis. PLoS One. 2015;10(10):e0139628.

37. Kafle RB, Dulal KP, Pandey KP. Continuum of maternal health care and the use of postpartum family planning in Nepal; 2017.
38. Do M, Kurimoto N. Women's empowerment and choice of contraceptive methods in selected African countries. Int Perspect Sex Reprod Health. 2012 38:23-33.

39. Yaya $\mathrm{S}$, et al. Women empowerment as an enabling factor of contraceptive use in sub-Saharan Africa: a multilevel analysis of cross-sectional surveys of 32 countries. Reprod Health. 2018;15(1):214

40. Mosha I, Ruben R, Kakoko D. Family planning decisions, perceptions and gender dynamics among couples in Mwanza, Tanzania: a qualitative study. BMC Public Health. 2013;13(1):523.

41. Koohi-Kamali F. Intrahousehold inequality and child gender bias in Ethiopia. The World Bank; 2008. https://doi.org/10.1596/1813-9450-4755.

42. Mace R, Eardley J. Maternal nutrition and sex ratio at birth in Ethiopia. Res Econ Anthropol. 2004;23:295-306.

43. Hesketh T, Xing ZW. Abnormal sex ratios in human populations: causes and consequences. Proc Natl Acad Sci. 2006;103(36):13271-5.

44. Rai $P$, et al. Effect of gender preference on fertility: a cross-sectional study among women of Tharu community from a rural area of the eastern region of Nepal. Reprod Health. 2014;11(1):15.

45. Jayachandran S. Fertility decline and missing women. Am Econ J Appl Econ. 2017:9(1):118-39.

46. Bongaarts J. The implementation of preferences for male offspring. Popul Dev Rev. 2013:39(2):185-208.

\section{Publisher's Note}

Springer Nature remains neutral with regard to jurisdictional claims in published maps and institutional affiliations.
Ready to submit your research? Choose BMC and benefit from:

- fast, convenient online submission

- thorough peer review by experienced researchers in your field

- rapid publication on acceptance

- support for research data, including large and complex data types

- gold Open Access which fosters wider collaboration and increased citations

- maximum visibility for your research: over $100 \mathrm{M}$ website views per year

At $\mathrm{BMC}$, research is always in progress.

Learn more biomedcentral.com/submissions 